\title{
Method of investment projects evaluation for territorial communities taking into account the concept of sustainable development
}

\author{
Nataliia Maksyshko*, Oksana Vasylieva, and Alyona Polova \\ Zaporizhzhia National University, Department of Economic Cybernetics, 66 Zhukovskogo Str., Zaporizhzhia, 69600, Ukraine
}

\begin{abstract}
The article is devoted to solving the problem of evaluation and selection of investment projects aimed at developing territorial communities, taking into account the concept of sustainable development. The problem of choosing from possible alternative solutions is not easy for decision makers and requires qualified justification. This is especially important in the context of decentralization reform, advancement of Ukraine towards society openness, increase of transparency requirements to the authorities and their results. Decision making on the basis of the sustainable development concept determines the evaluation of investment projects in terms of their effectiveness in solving problems of social, economic and environmental nature, finding a balance between these components. The peculiarity of the assessments is not so much quantitative as qualitative character, which makes it expedient to use the apparatus of fuzzy logic. The fuzzy model of evaluation of investment project aimed at developing a territorial community is constructed and substantiated in the work. The model is based on quantitative and qualitative evaluations of the social, economic and environmental components of the concept and enables a "soft" - qualitative evaluation of the investment project under consideration. Modeling results are based on the method of deciding on the choice of investment projects for the development of territorial communities. The proposed model and method are implemented by the Fuzzy Logic Toolbox application, were applied to substantiate decisions for the territorial community of Zaporizhzhia region, and can be used in the development of decision support systems to quantify the decisions and variant calculations.
\end{abstract}

\section{Introduction}

The challenges of the 21 st century make it necessary to ensure economic growth in the country on a balance basis. This implies the inheritance by descendants of all environmental components in a condition no worse than exists today. This is the concept of sustainable development, which was first emphasized in 1987 in the report "Our Common Future" by the International Commission on Environment and Development [1].

This concept provides an opportunity to provide comprehensive management of territorial socioeconomic systems, integrates the agreed aspects of economic, environmental and social development of society, creates conditions under which from one generation to the next the quality and safety of human life will not diminish, the environment will not deteriorate and socio-economic progress will be ensured [2].

Ensuring balanced development of the regions is one of the priority directions of Ukraine's regional policy at the present stage of its transformational changes. Achieving this priority is facilitated by decentralization reform, which aims at the enhancing self-development of territorial socio-economic systems, their self- regulation, self-improvement with efficient use of available internal and external resources to meet the needs of residents $[3,4]$.

The task of decentralization reform is to create the conditions for local issues to be addressed independently. Thus, in the light of global trends, the newly formed United Territorial Communities (UTCs) face the need to create a system of governance that would provide prospects for the development of the territory not only from the point of view of socioeconomic efficiency, but also by adhering to the principles of sustainable development oriented on interest of future generations. The Sustainable Development Goals, which were endorsed in 2015 at the United Nations Summit [5], are the baseline that sets out the forward-looking trends of the world, Ukraine and, in particular, the UTCs.

Each territorial community is tasked with identifying areas and means that will enable sustainable development, both in the long term and at every step of government.

Thus, the issue of raising capital for the environmentally-oriented development of both the economy of Ukraine and individual communities is currently acute. Ukrainian experts [6] point out that the

\footnotetext{
* Corresponding author: maxishko@ukr.net
} 
implementation of European integration reforms in the environmental sector of Ukraine requires the introduction of a "green" economy and development of territorial communities, ensuring human rights for a clean environment, decent work. The level and quality of the population life, as well as the development of human capital, depend on the social aspects of investment. But today, UTCs do not always understand and take into account the importance of social aspects of investing.

The problem of choosing from possible alternative solutions is usually not easy for decision makers and requires qualified justification. This is especially important in the context of Ukraine's move towards openness of society, increasing demands for transparency of government actions and their results.

The scientific works of both domestic and foreign scientists [7-11] are devoted to the study of socioecological and economic development of the region, in particular those related to the development of models for assessing its level. The studies that focus on the quality of investment projects at regional level [12-15] take into account only certain aspects (environmental, social or economic). The paper [16] proposes a multicriteria approach to the selection of investment projects. However, the development of regional systems for the united territorial communities, particularly that comprehensively take into account the requirements of sustainable development is missing.

In these circumstances, it is extremely important to develop and apply models and methods of quantitative and qualitative substantiation of the decisions made by the united territorial communities and aimed at solving problems of social, economic and environmental character in order to improve their own well-being and quality of life.

The purpose of this work is to develop and validate a fuzzy model for evaluating the quality of investment projects for territorial communities, taking into account the concept of sustainable development and recommendations for its application in the process of strategic decision-making for the community.

\section{Materials and methods}

The essence of the problem, which is devoted to this work, lies in the evaluation and comparative analysis of investment projects. These projects are presented to the local community leadership (UTC) for choice and will depend on its further development in the context of implementing a sustainable development strategy.

Sustainable development of territories is ensured by a combination of environmental, economic and social components (spheres), each of which can be assessed by a whole set of relevant indicators.

For further modeling of the development level for UTC as a result of realization of the investment project for each component one measurable indicator is selected, which in the further researches can be replaced by, for example, an integral indicator for a certain sphere. Each of these marks (indicators) characterizes the effectiveness of an investment project for an UTC in terms of a specific area.

It should be noted that the choice of a measured indicator faces the problem of choosing a measurement scale and methods of its measurement / calculation. If a quantitative indicator can be chosen to evaluate the level of economic development, for example, the rate of increase / decrease in community budget revenues resulting from the project implementation, and to evaluation the social impact can be use the number of jobs that will be created during the project implementation, then the environmental component is not always suitable for formal quantitative measurement procedure. Therefore, often only expert evaluation can be used to measure it. However, confidence in such evaluations may be different. Thus, the rating system, which characterizes the effectiveness of the investment project implementation, can contain both quantitative and qualitative indicators.

With this in mind, we come to the conclusion that in order to solve the problem of evaluating investment projects in the context of the concept of sustainable development and to make management decisions on the development of an UTC, it is advisable to use data mining tools, namely fuzzy modeling.

Its founders - L. Zade [17], D. Dubois, A. Prad, A. Kofman devoted their research to problems of the use of a fuzzy logic for the analysis of economic systems. The works of A. Matviychuk [18], A. Nedosekin, S. Orlovsky, S. Stovby, N. Maksyshko, V. Shapovalova [19], E. Kanaeva [20] and others are devoted to the improvement of decision-making methods in the economy based on the use of a fuzzy modeling methods.

The methodology for constructing a fuzzy model, including to obtain a qualitative assessment of an investment project for the development of an UTC, taking into account the concept of sustainable development, consists of the following stages:

- formation of a base for a fuzzy model input variables;

- fuzzification of input and output variables;

- formation of a fuzzy logic rules base;

- accumulation of conclusions based on fuzzy rules;

- defuzzification of the output variable (figure 1).

Method of investment projects evaluation for territorial communities is based on use of the constructed fuzzy model. The fuzzy model allows to bring the totality of quantitative and qualitative evaluations to a single quantitative scale: rating, which makes it possible to compare projects by different areas (economic, social and environmental).

A fuzzy model for evaluating the investment projects attractiveness is used to benchmark projects on the development of an UTC in line with the sustainable development concept. The general scheme of the decision-making method for choosing an investment project is presented in figure 2 .

The Fuzzy Logic Toolbox Editor, a built-in application to Mathworks, is used to implement a fuzzy model for evaluating an investment project for the development of an UTC. 


\section{Results}

A fuzzy model of evaluating the investment projects attractiveness for integrated territorial communities is built, based on the use of fuzzy logic and taking into account the sustainable development concept.
The first two stages of fuzzy model construction are done in parallel. In the first stage the variables and the set of their linguistic terms are defined, and in the second stage - the fuzzification - the sets of variable definition and the type of membership functions are specified.

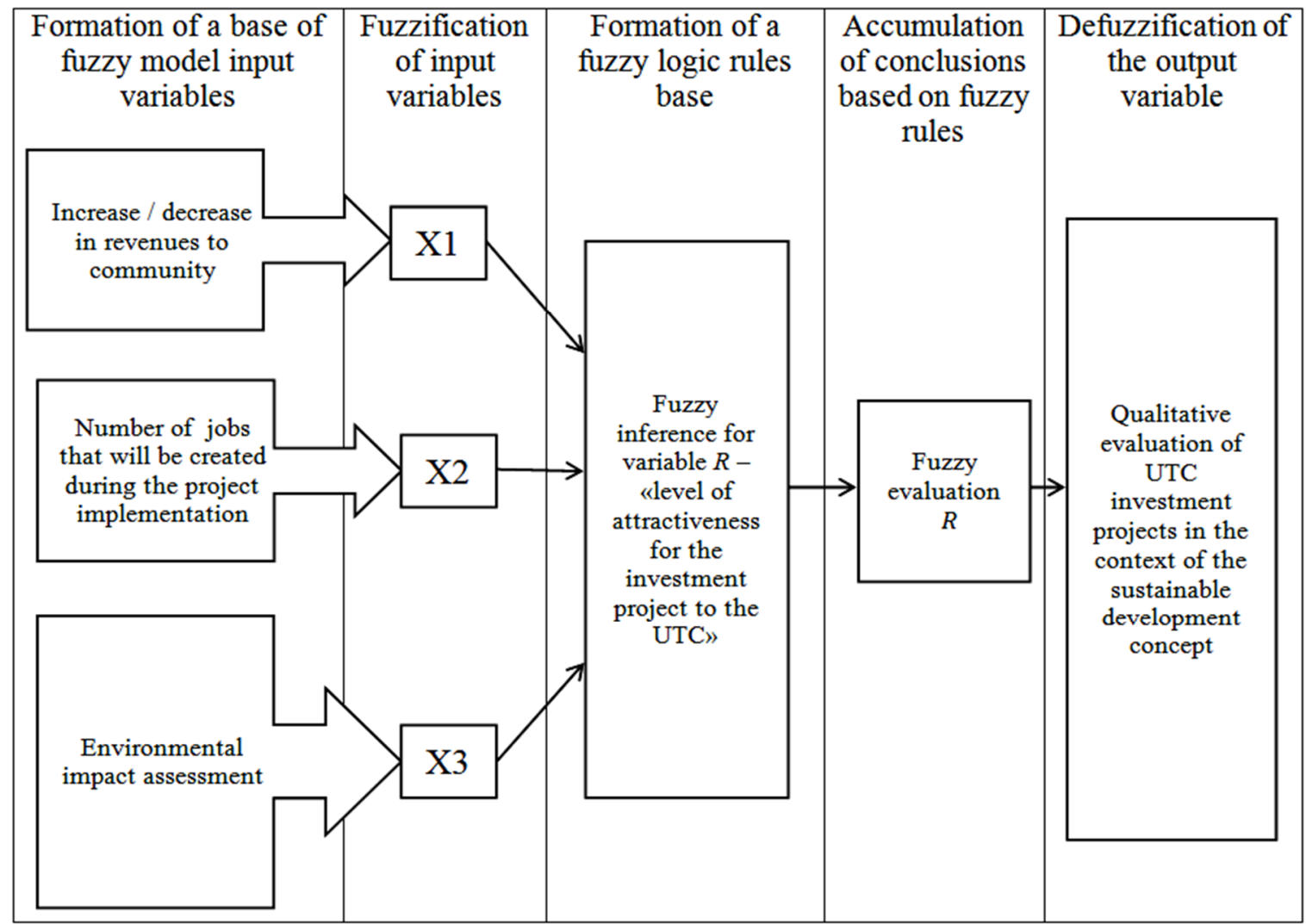

Fig. 1. The general scheme of fuzzy model construction for investment project evaluation to the development of an UTC.

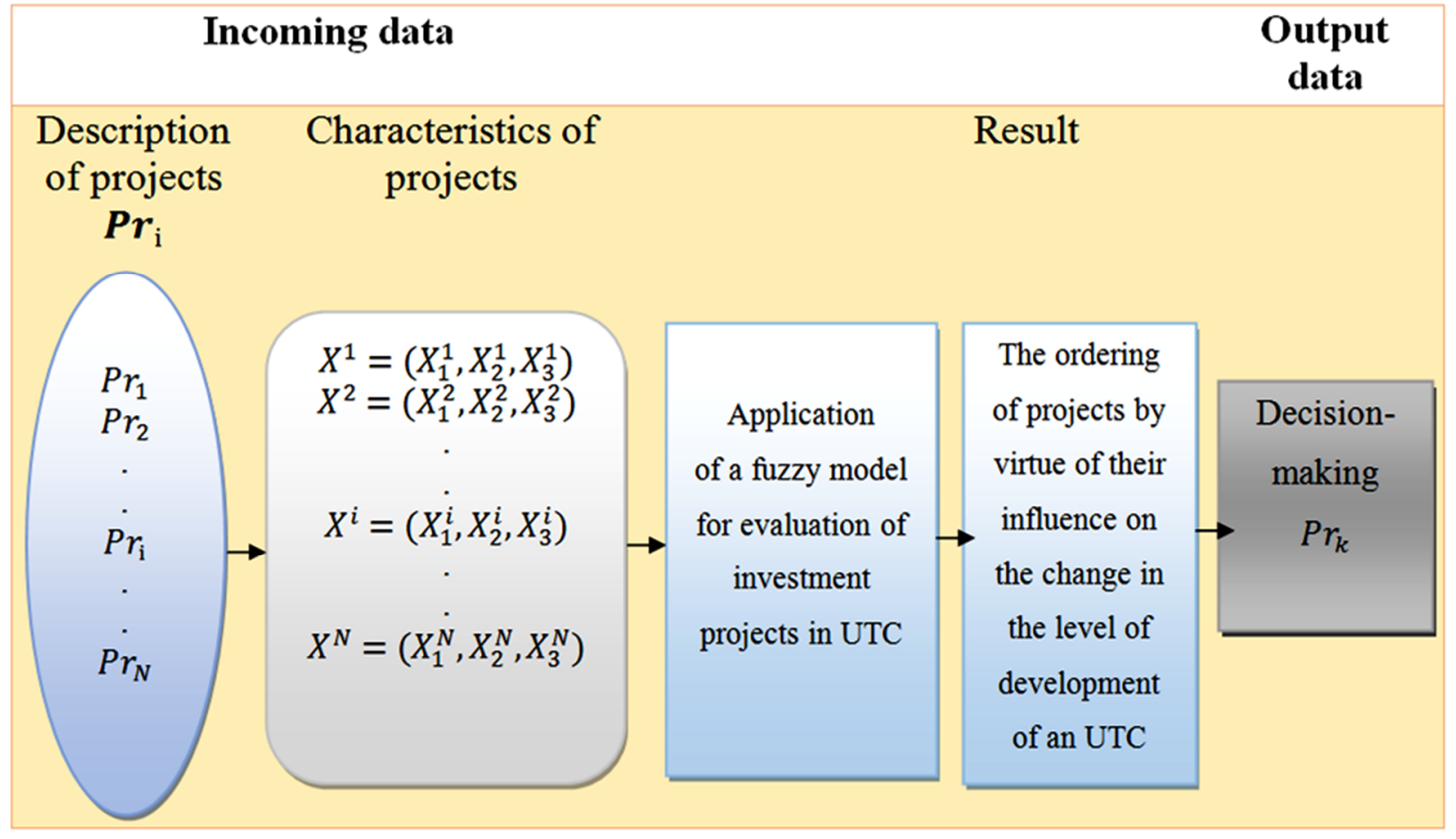

Fig. 2. The general scheme of the method of deciding on the choice of investment project to the development of an UTC. 
Variable $\mathrm{X}_{1}$ reflects the rate of increase / decrease in community budget revenues. This indicator characterizes the relative changes (\%) in budget revenues resulting from the project implementation.

The variable $X_{1}$ is calculated by the formula:

$$
X_{1}=\frac{\mathrm{F}_{i}}{\mathrm{~F}_{i-1}} \times 100 \%
$$

where $X_{1}$ - economic growth (\%);

$\mathrm{F}_{i}$ - the amount of budget revenues after project implementation (at time $i$ );

$\mathrm{F}_{i-1}$ - the amount of budget revenues before the project implementation (at time $i-1$ ).

Based on the analysis of existing investment business projects, interval $[70 ; 150]$ is chosen for the values set of variable $X_{1}\left(X_{1} \in[70 ; 150]\right)$. The $70 \%$ limit is explained by the fact that, despite the potential environmental and social benefits of the investment, the project will not be considered if its losses can exceed $30 \%$ of the community budget. The upper limit is set at $50 \%$ of all budget revenues and is 150 . Variable $\mathrm{X}_{1}$ is given by three linguistic variables (term-sets). Their fuzzification parameters are shown in table 1 .

Table 1. Fuzzification of the Economic Growth variable $\left(X_{1}\right)$.

\begin{tabular}{|c|c|c|}
\hline $\begin{array}{c}\text { Linguistic } \\
\text { assessment }\end{array}$ & $\begin{array}{c}\text { View membership } \\
\text { function }\end{array}$ & Function options \\
\hline Decrease & trapezoidal & {$[70 ; 70 ; 90 ; 100]$} \\
\hline Permanence & triangular & {$[93 ; 100 ; 107]$} \\
\hline Increase & trapezoidal & {$[100 ; 120 ; 150 ; 150]$} \\
\hline
\end{tabular}

A visual representation of variable $X_{1}$ is shown in figure 3 .

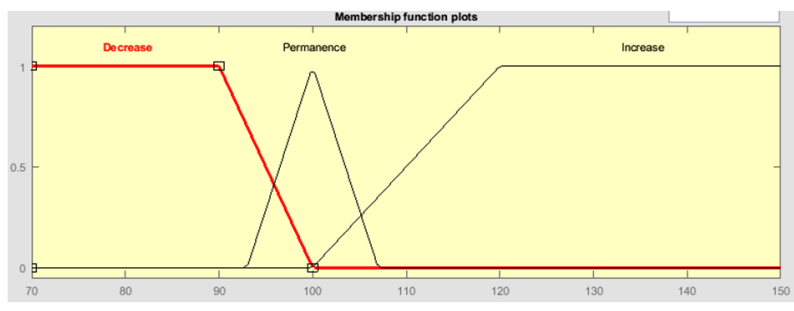

Fig. 3. Graphical representation for the term-sets of Economic growth variable $\left(X_{1}\right)$.

The choice of the triangular membership function for linguistic assessment "Permanence" is explained by the fact that only the value 100 fully corresponds to the term "stable" and the value of the membership function $\mu$ of the linguistic variable "Permanence" at $X_{1}=100$ equals one $\left(\mu^{\text {Permanence }}(X 1=100)=1\right)$. When deviation from 100 in intervals $[93 ; 100)$ and $(100 ; 107]$ the membership function decreases linearly to zero.

The linguistic variables "Increase" and "Decrease" are better described by the trapezoidal function, since the membership functions $\mu$ are equal to 1 not only at one discrete value $X_{1}$, but at the interval $X_{1} \in[70 ; 90]$ : $\mu^{\text {Decrease }}\left(X_{1}\right)=1$ and $X_{1} \in[120 ; 150]: \mu^{\text {Increase }}\left(X_{1}\right)=1$.

The next variable is $\mathrm{X} 2$ which takes into account the social inclusion from the project. Input variable $\mathrm{X} 2$ is estimated as a percentage reduction in community unemployment (calculated as the ratio of the jobs created number during the project to the total number of unemployed communities):

$$
X_{2}=\frac{W}{\mathrm{U}} \times 100 \%,
$$

where $X_{2}-$ Social inclusion (\%);

$W$ - number of new jobs created during the project implementation;

$U$ is total number of unemployed communities.

The value of variable $X_{2}$ is within $X_{2} \in[0 ; 100]$. Thus, if no new jobs are created during the investment, then $X_{2}=0$, if the number of jobs created is equal to the number of unemployed communities, then $X_{2}=100$ $(\%)$. In case where the number of jobs exceeds the number of unemployed persons should be considered separately and are not the subject of this study, as they cover the issue of changing the social policy of the community regarding labor attraction.

The basic fuzzification parameters for variable $X_{2}$ are shown in table 2 .

Table 2. Fuzzification of the Social inclusion variable $\left(X_{2}\right)$.

\begin{tabular}{|c|c|c|}
\hline $\begin{array}{c}\text { Linguistic } \\
\text { assessment }\end{array}$ & View membership function & Function options \\
\hline Slight & triangular & {$[0 ; 0 ; 20]$} \\
\hline Medium & triangular & {$[10 ; 30 ; 50]$} \\
\hline Significant & trapezoidal & {$[30 ; 60 ; 100 ; 100]$} \\
\hline
\end{tabular}

The visual representation of variable $X_{2}$ is shown in figure 4 .

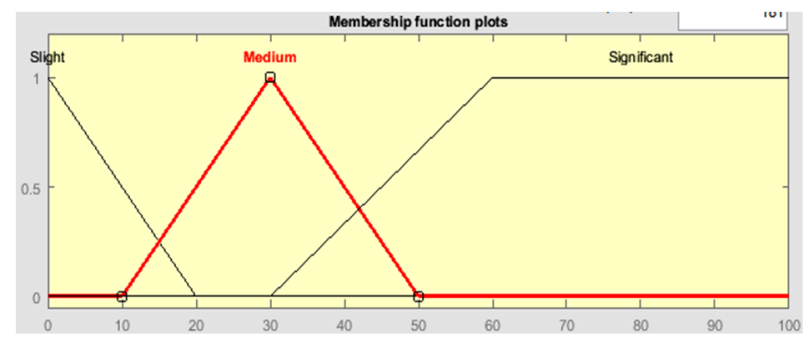

Fig. 4. Graphical representation for the term-sets of Social inclusion variable $\left(X_{2}\right)$.

The variable X3 characterizes the environmental effect that the investment project has on the environment. The value of X3 is determined on the basis of expert evaluation, measured in points and is in the interval: $\mathrm{X} 3 \in[-100 ; 100]$. That is, at the most destructive value of environmental impact $\mathrm{X} 3=-100$, with neutral impact $\mathrm{X} 3=0$, and at the most positive $\mathrm{X} 3=100$. The basis for the determination of variable $\mathrm{X} 3$ can be the environmental impact assessment report conducted on the basis of Law of Ukraine No. 2059VIII [15] or calculations, for example, by the method [12].

The basic fuzzification parameters for variable $X_{3}$ are shown in table 3 .

A visual representation of the variable $X_{3}$ is shown in figure 5.

The application of the five linguistic variables and Gaussian membership functions is explained by the complexity of the procedure for formalizing 
environmental impact assessment, which is determined only by expert opinion. The Gaussian type of membership function is analogous to the normal law of distribution for random variable. This law is the most inherent in natural environmental processes.

Table 3. Fuzzification of the Environmental protection variable $\left(X_{3}\right)$.

\begin{tabular}{|c|c|c|}
\hline $\begin{array}{c}\text { Linguistic } \\
\text { assessment }\end{array}$ & $\begin{array}{c}\text { View membership } \\
\text { function }\end{array}$ & $\begin{array}{c}\text { Function } \\
\text { options }\end{array}$ \\
\hline Extremely negative & Gaussian & {$[-20 ;-100]$} \\
\hline Negative & Gaussian & {$[15 ;-50]$} \\
\hline Neutral & Gaussian & {$[10 ; 0]$} \\
\hline Positive & Gaussian & {$[15 ; 50]$} \\
\hline Extremely positive & Gaussian & {$[20 ; 100]$} \\
\hline
\end{tabular}

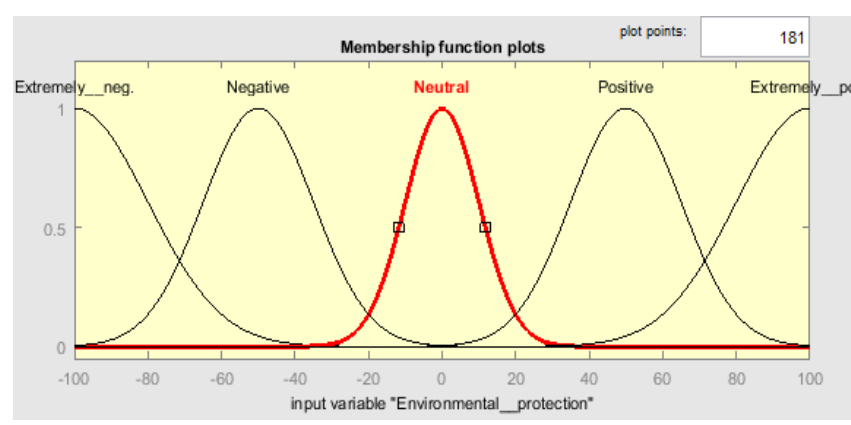

Fig. 5. Graphical representation for the term-sets of Environmental protection variable $\left(X_{3}\right)$.

Using the three input variables that characterize the economic, social and environmental impact of the project, it is necessary to obtain an integrated investment rating - the output variable $R$, which indicates the level of attractiveness for the investment project to the UTC (measured in points). Let variable R is defined in the interval $[0 ; 100]$, where $\mathrm{R}=0$ corresponds to an absolutely unattractive investment and $\mathrm{R}=100$ to an absolutely attractive investment. The main fuzzification parameters of the variable $\mathrm{R}$ are given in table 4.

Table 4. Fuzzification of the variable $R$ - rating of investment attractiveness.

\begin{tabular}{|c|c|c|}
\hline $\begin{array}{c}\text { Linguistic } \\
\text { assessment }\end{array}$ & $\begin{array}{c}\text { View membership } \\
\text { function }\end{array}$ & $\begin{array}{c}\text { Function } \\
\text { options }\end{array}$ \\
\hline Slight & triangular & {$[0 ; 0 ; 35]$} \\
\hline Medium & triangular & {$[25 ; 50 ; 75]$} \\
\hline Significant & triangular & {$[65 ; 100 ; 100]$} \\
\hline
\end{tabular}

A visual representation of the variable $\mathrm{R}$ is shown in figure 6 .

The next stage is a building a fuzzy knowledge base and decision-making rules.

The rules are based on the following considerations. First, let's set the rules for the extreme values of $X_{3}$ - the environmental component. If the value of $X_{3}$ is "Extremely negative", then the investment rating will be low, regardless of the $X_{1}$ and $X_{2}$ values. This means that with significant damage to the environment, despite the possible high economic or social effect, the attractiveness of this project will be considered low.

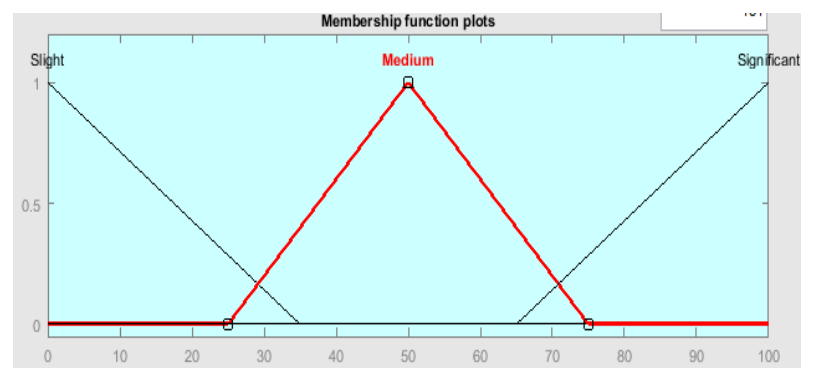

Fig. 6. Graphic representation for the term-sets of output variable $R$.

Accordingly, with the Extremely positive value of the environmental component, the benefit of the investment will be considered significant, regardless of the economic or social component. Recall that the negative economic effect is limited to $30 \%$ when determining the input value X1 (projects that lead to a decrease in community budget revenues by more than $30 \%$ are not considered).

Other rules of the fuzzy knowledge database are presented in the form of table 5 .

Table 5. Knowledge base for variable $R$ - rating of the investment attractiveness.

\begin{tabular}{|c|c|c|c|c|}
\hline \multicolumn{2}{|c|}{ Variables } & $\begin{array}{c}\text { X3 } \\
\text { (Negative) }\end{array}$ & $\begin{array}{c}\text { X3 } \\
\text { (Neutral) }\end{array}$ & $\begin{array}{c}\text { X3 } \\
\text { (Positive) }\end{array}$ \\
\hline X1 & X2 & R & R & R \\
\hline Decrease & Slight & Slight & Slight & Slight \\
\hline Decrease & Medium & Slight & Slight & Medium \\
\hline Decrease & Significant & Slight & Slight & Medium \\
\hline Permanence & Slight & Slight & Slight & Medium \\
\hline Permanence & Medium & Slight & Medium & Significant \\
\hline Permanence & Significant & Slight & Significant & Significant \\
\hline Increase & Slight & Slight & Significant & Significant \\
\hline Increase & Medium & Medium & Significant & Significant \\
\hline Increase & Significant & Medium & Significant & Significant \\
\hline
\end{tabular}

Based on the Table 5 and the assertions of extreme values of environmental effects generated 16 rules:

1. If (Environmental protection is Extremely negative) then (Rating is Slight).

2. If (Environmental protection is Extremely positive) then (Rating is Significant).

3. If (Economic growth is Decrease) and (Environmental protection is Negative) then (Rating is Slight).

4. If (Economic growth is Decrease) and (Environmental protection is Neutral) then (Rating is Slight).

5. If (Economic growth is Increase) and (Environmental protection is Positive) then (Rating is Significant).

6. If (Economic growth is Permanence) and (Environmental protection is Negative) then (Rating is Slight).

7. If (Economic growth is Increase) and (Social inclusion is Slight) and (Environmental protection is Negative) then (Rating is Slight).

8. If (Economic growth is Increase) and (Social inclusion is not Slight) and (Environmental 
protection is Negative) then (Rating is Medium).

9. If (Economic growth is Permanence) and (Social inclusion is Slight) and (Environmental protection is Neutral) then (Rating is Slight).

10. If (Economic growth is Permanence) and (Social inclusion is Medium) and (Environmental protection is Neutral) then (Rating is Medium).

11. If (Economic growth is Permanence) and (Social inclusion is Significant) and (Environmental protection is Neutral) then (Rating is Significant).

12. If (Economic growth is Increase) and (Environmental protection is Neutral) then (Rating is Significant).

13. If (Economic growth is Decrease) and (Social inclusion is Slight) and (Environmental protection is Positive) then (Rating is Slight).

14. If (Economic growth is Decrease) and (Social inclusion is not Slight) and (Environmental protection is Positive) then (Rating is Medium).

15. If (Economic growth is Permanence) and (Social inclusion is Slight) and (Environmental protection is Positive) then (Rating is Medium).

16. If (Economic growth is Permanence) and (Social inclusion is not Slight) and (Environmental protection is Positive) then (Rating is Significant).

Mamdani fuzzy inference system is used to build the model. This choice is due to the lack of a statistical sample of quantified evaluation for the indicators under study, the qualitative nature of the variables X3 (environmental component) and $\mathrm{R}$ (rating of the investment project).

As a result of the model, it is possible to build a surface that gives a graphical idea of the project rating depending on the input indicator values (fig. 7).

The constructed model can be applied to support decision-making in the development and justification of a strategic plan for the development of united territorial communities.

To verify the model, let's test it on the example of Veselovsky United Territorial Community of Veselovsky district of Zaporizhzhia region. According to the official site of Veselivska UTC, the population (excluding preschool and school-age children) is 10640 people, and the amount of income (estimated) of the territorial community is 12.679 million UAH [22]. According to the State Statistics Service of Ukraine, the average unemployment rate in the Zaporizhzhya region is $9.9 \%$ among the population aged $15-70$ years [23]. Then the number of unemployed Veselovskaya OTG is approximately 1,053 persons.

Consider two alternative investment projects for the development of the territorial community: the traditional activity for Ukrainian farmers is sunflower cultivation and the innovative approach is the construction of a solar power plant.

Let's look at project characteristics in more detail.

Project 1 - Sunflower cultivation.

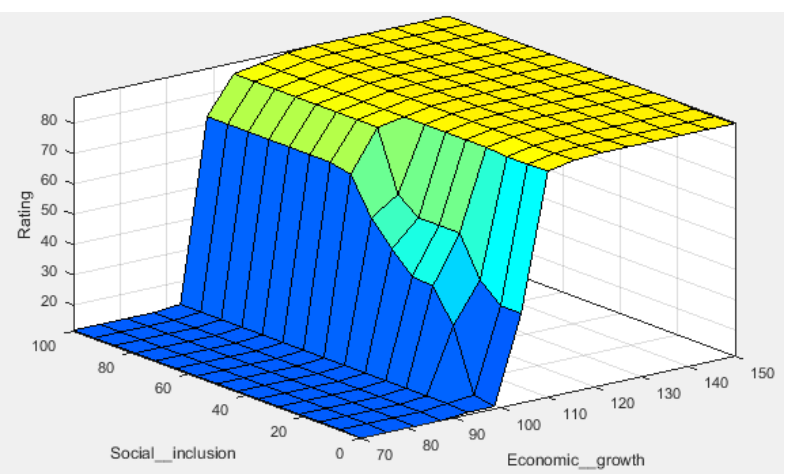

a)

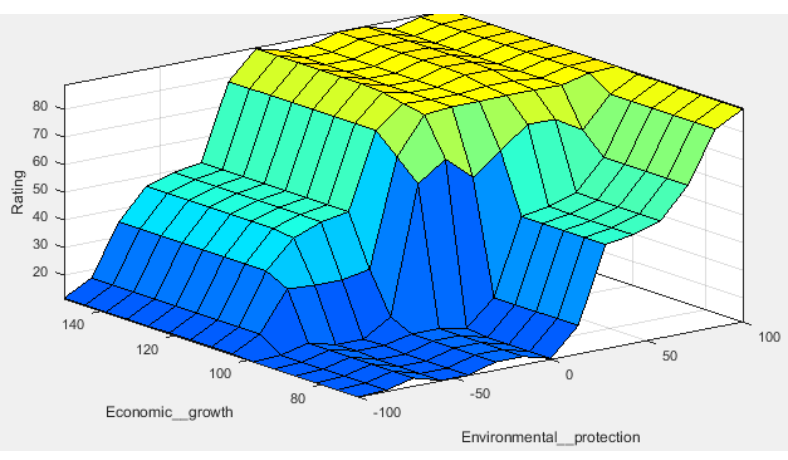

b)

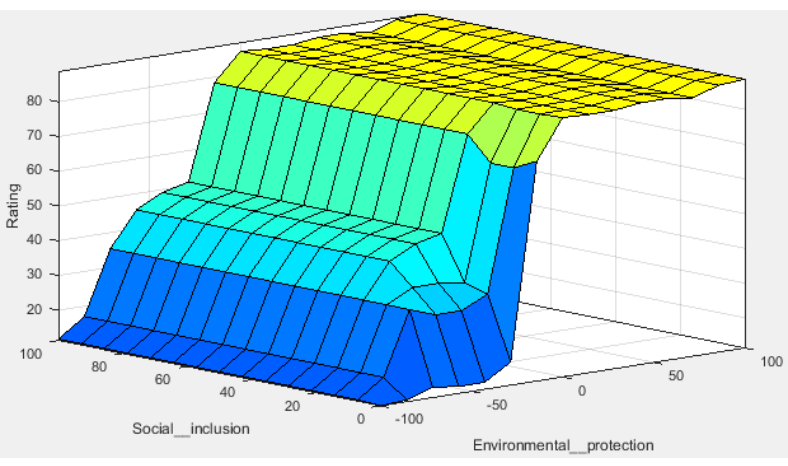

c)

Fig. 7. The output surface for the variables: a) Social inclusion $\left(X_{2}\right)$ and Economic growth $\left(X_{1}\right)$; b) Economic growth $\left(X_{1}\right)$ and Environmental protection $\left(X_{3}\right)$; c) Social inclusion $\left(X_{2}\right)$ and Environmental protection $\left(X_{3}\right)$.

Sunflower growing is a profitable business, it is the most profitable oilseed crop in our country. The basic data for the calculation were obtained from the source [24], in particular, the results of sunflower cultivation of LLC "Dokuchaevsky Chernozem", Karlovsky district of Poltava region.

It is known that the territorial community is considering the use of 20 hectares of land owned by it.

The costs of growing and harvesting in this case amount to 280 thousand UAH, the increase in cash flow from the project is also 280 thousand $\mathrm{UAH}$. The number of jobs created is 10 .

The cultivation of sunflower is associated with such negative effects as the depletion and drying of the soil, increased water and wind erosion [25]. The cultivation of sunflower is associated with such negative effects as 
the depletion and drying of the soil, increased water and wind erosion. Considering that the problem of soil depletion and erosion can be solved, and the problem of drying is smoothed by the correct cultivation of land, the expert assessment of environmental impact is 10 points.

Thus, the input variables of the sunflower cultivation project are:

$$
\begin{aligned}
& X_{1}=102.2 \% \\
& X_{2}=1 \% \\
& X_{3}=-10 \text { points. }
\end{aligned}
$$

The result of the evaluation for project 1 in the defuzzification stage is shown in figure 8 .

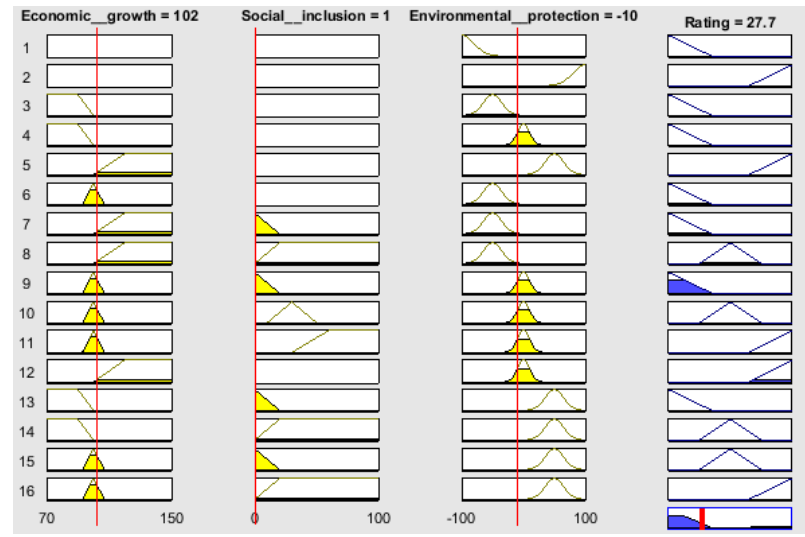

Fig. 8. Rule Viewer for sunflower growing.

According to the results of the evaluation, the attractiveness of this investment is 27.7 points out of 100 possible.

Project 2 - construction of a solar power plant.

A solar grid power plant is used to sell electricity to the grid at a "green" rate.

Suppose that solar power plant wants to build on a plot of 20 ha.

The cost of its construction is $\$ 8$ million, the profitability of the project will be $25.3 \%$, the payback period of the project -5 years. As a result, we receive $\$ 2.078$ million revenues, 25 jobs, and a positive environmental impact assessment at 50 points (used for calculations [26]).

However, it should be noted that the territorial community does not have the financial resources to implement such a large-scale, in terms of initial investment, project, so the implementation of this project is possible only with the participation of the investor. If the community finds an investor and receives only land and taxes, the annual income will be 250,000 UAH.

Thus, the input variables of a project involving an investor to build a solar power plant are:

$X_{1}=101.9 \%$;

$X_{2}=2.4 \%$

$X_{3}=50$ points.

The results of the evaluation of project 2 in the defuzzification step are shown in figure 9.

The attractiveness of the project for the construction of a solar power plant with the involvement of the investor is 54.5 points out of 100 , which is almost twice better than the project for growing sunflower.

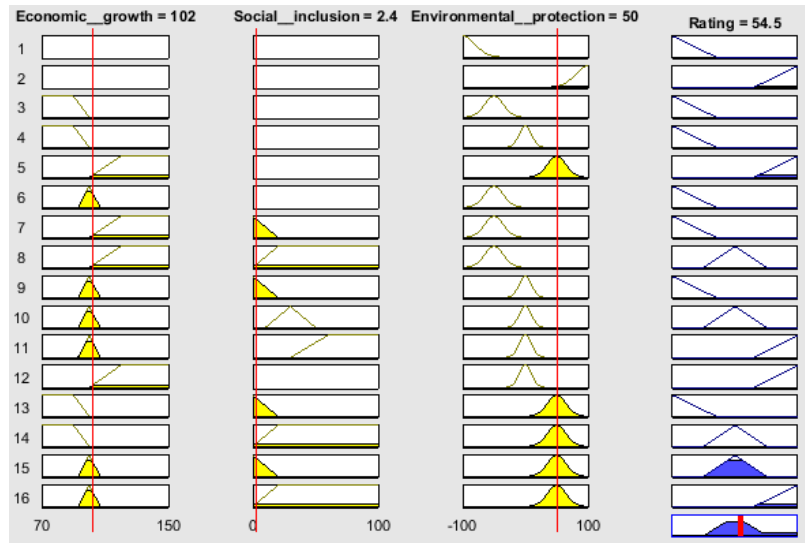

Fig. 9. Rule Viewer for attracting an investor to build a solar power plant.

Thus, the results of applying the fuzzy logic method and deciding on the choice of an investment project for the development of the UTC have shown that Project 2 is the most beneficial.

Although the budget of the community does not allow allocating sufficient amount of money for the construction of its own solar power plant, the decision to build a solar power plant with the involvement of investors is more advantageous than the cultivation of sunflower. Of course, the community income will be less than if the power plant belonged to the community, and the number of jobs and the share of electricity generated from renewable sources will remain unchanged.

\section{Conclusion}

The concept of sustainable development at the level of territorial communities aims at harmonious and balanced management of their resources in order to ensure social, economic and ecological development of the community, increase its economic potential, create a complete living environment for modern and future generations.

The achievement of this goal is facilitated by the decentralization reform, which requires the formation of an effective system for public authority. The powers delegation to the local level activates the economic activity of local self-government bodies, motivates them to use their existing potential effectively and rationally, to take management decisions to find alternatives and additional opportunities for increase the competitiveness of territorial communities.

Decision-making at the territorial community level to provide additional services to local residents, improve their living conditions, create a full living environment is of central importance in the implementation of the sustainable development concept. At the same time, important aspects of this activity are its publicity, transparency, interests' coherence of the authorities, business and the public.

Managing the development of a territorial community requires a constant search for a balance 
between its economic, social and environmental components, involving all stakeholders in the decisionmaking process; flexibility and effectiveness of management actions.

All these problems and tasks will necessitate the widespread use of new digital technologies (digitization) to optimize and automate decision-making processes, ensure transparency of decisions, and improve communication with community members. There is a need to develop and improve decision support systems which accumulate databases that available in the community and databases of models that address management challenges.

In this work, a fuzzy model of investment project evaluation is developed and substantiated. It is aimed at the development of a territorial community, based on taking into account its qualitative assessments in terms of the main components of the sustainable development concept. This model makes it possible to give a "soft" qualitative evaluation of the investment project under consideration, while taking into account not only its quantitative but also qualitative characteristics.

The model has the potential for further improvement due to the detailing of the process of evaluating the component indicators, the formation of a branched tree of goals, the extension of gradations (the number of terms) of qualitative estimates, determining the benefits of each indicator for a particular community, etc.

However, the proposed model has already been the basis of the decision-making method for selecting investment projects for the territorial community' development, based on a comparative analysis of their qualitative assessments.

The proposed method has been tested for making decisions on the choice of investment project based on the data of the Veselivska United Territorial Community of Veselivsky District of Zaporizhzhia Region.

As a result of applying the fuzzy evaluation model, a comparative analysis of two investment projects Sunflower Growing and Solar Power Plant Construction - was made. The results of the calculations showed that all the parameters of the model are correctly defined and all the necessary information for their calculation is available. The management of the territorial community confirmed the expediency of deciding on the choice of investment project, which was obtained as a result of the application of the developed method (construction of a solar power plant with the involvement of investors).

The use of standard mathematical software (Fuzzy Logic Toolbox application) creates opportunities for model implementation and its application in the development of territorial decision support systems to quantify decisions and to make variant calculations for choosing the best investment options.

\section{References}

1. G.H. Brundtland, Our common future (KP SDG UNDESA, 1987), https://sustainabledevelopment.un.org/content/docu ments/5987our-common-future.pdf. Accessed 10 Feb 2020

2. J. Mensah, S.R. Casadevall, Sustainable development: Meaning, history, principles, pillars, and implications for human action: Literature review. Cogent Social Sciences 5, (2019). doi:10.1080/23311886.2019.1653531

3. Legislation of Ukraine, The concept of local government reform and territorial organization of power in Ukraine, no. 333-2014-p, 01.04.2014, https://zakon.rada.gov.ua/laws/show/333-2014$\%$ D1\%80\#n8. Accessed 12 Feb 2020

4. D.M. Melnyk, Agrosvit 11, 33 (2018)

5. Sustainable Development Goals 2016-2030 (UN Ukraine), http://www.un.org.ua/ua/tsili-rozvytkutysiacholittia/tsili-staloho-rozvytku. Accessed 12 Feb 2020

6. O.V. Latysheva, Economic Bulletin of Donbass 1(51), 59 (2018)

7. V.I. Voronenko, Agrosvit 12, 71 (2015)

8. Yu.M. Kharazishvili, Bulletin of economic science of Ukraine 1(30), 149 (2016)

9. Yu. Matvieieva, Yu. Myroshnychenko, Economy and state 8, 35 (2017)

10. S. Thacker, D. Adshead, M. Fay, S. Hallegatte, M. Harvey, H. Meller, N. O’Regan, J. Rozenberg, G. Watkins, J.W. Hall, Infrastructure for sustainable development. Nature Sustainability 2(4), 324 (2019)

11. G. Duranton, A. Venables, Policy research working paper no. WPS 8410 (World Bank Group, Washington, 2018),

http://documents.worldbank.org/curated/en/547051 523985957209/Place-based-policies-fordevelopment. Accessed 03 Jan 2020

12. S. Ziyadin, E. Streltsova, A. Borodin, N. Kiseleva, I. Yakovenko, E. Baimukhanbetova, Assessment of Investment Attractiveness of Projects on the Basis of Environmental Factors. Sustainability 11(9), 16 (2019). doi:10.3390/su11092544

13. T. Anopchenko, O. Gorbaneva, E. Lazareva, A. Murzin, G. Ougolnitsky, Modeling PublicPrivate Partnerships in Innovative Economy: A Regional Aspect. Sustainability 11(20), 18 (2019). doi:10.3390/su11205588

14. V. Medvid, V. Pylypenko, N. Pylypenko, T. Ustik, N. Volchenko, M. Vashchenko. Factors of rural development in the context of decentralisation: empirical research. Economic Annals-XXI 177 (56), 126-140 (2019). doi:10.21003/ea.V177-11

15. V. Glazkova. Principles of sustainable development of the economy within the evaluation of the efficiency of social innovative-and-investment projects. MATEC Web of Conferences 106, 08096 (2017). doi:10.1051/matecconf/201710608096

16. O.A. Shvetsova, E.A. Rodionova, M.Z. Epstein, Evaluation of investment projects under 
uncertainty: multi-criteria approach using interval data. Entrepreneurship and Sustainability Issues 5(4), 914-928 (2018).

doi:10.9770/jesi.2018.5.4(15)

17. L.A. Zadeh, Fuzzy sets. Information and Control. 8(3), 338-353 (1965). doi:10.1016/S00199958(65)90241-X

18. A.V. Matviichuk, Shtuchnyi intelekt v ekonomitsi: neironni merezhi, nechitka lohika (Artificial Intelligence in Economics: neural networks, fuzzy logic). (KNEU, Kyiv, 2011)

19. V.O. Shapovalova, N.K. Maksyshko, Neuro-fuzzy modeling technologies in economics 3, 94 (2014)

20. E.M. Kanaeva, Model' ocenki investicionnyh proektov na osnove nechetkih mnozhestv vtorogo porjadka (Model evaluation of investment projects based on type-2 fuzzy sets). Postulat 6 (2019), http://e-postulat.ru/index.php/Postulat/article/view /2757. Accessed 1 Feb 2020

21. Legislation of Ukraine, On environmental impact assessment, no. 2059-VIII, 23.05.2017, https://zakon.rada.gov.ua/laws/show/2059-19.

Accessed 01 Feb 2020

22. Veselivska settlement territorial community (20152020), https://veselivska-gromada.gov.ua/. Accessed 12 Feb 2020

23. State statistics service of Ukraine (Basic indicators on labour market, 2019), http://www.ukrstat.gov.ua/. Accessed 12 Feb 2020

24. Landlord, Spetsproekt. Rentabelnist soniashnyka (Special project: profitability of sunflower). (2019), https://landlord.ua/wp-content/page/rentabelnistsoniashnyka-spetsproekt/. Accessed 10 Feb 2020

25. O. Goncharov, Soniashnyk $i$ rodiuchist hruntu (Sunflower and soil fertility). (2016), https://agro.dn.gov.ua/najchastishe-girshesonyashnik-i-rodyuchist-gruntu/. Accessed 03 Jan 2020

26. KB Energy, https://kbenergy.com.ua. Accessed 03 Jan 2020 